\title{
Enhanced Photothermal Effect of Surface Oxidized Silicon Nanocrystals Anchored to Reduced Graphene Oxide Nanosheets
}

\author{
Parichehr Afshani, Sherif Moussa, Garrett Atkinson, Vitaly Y. Kisurin, and \\ M. Samy El-Shall* \\ Department of Chemistry, Virginia Commonwealth University, Richmond, VA, 23284
}

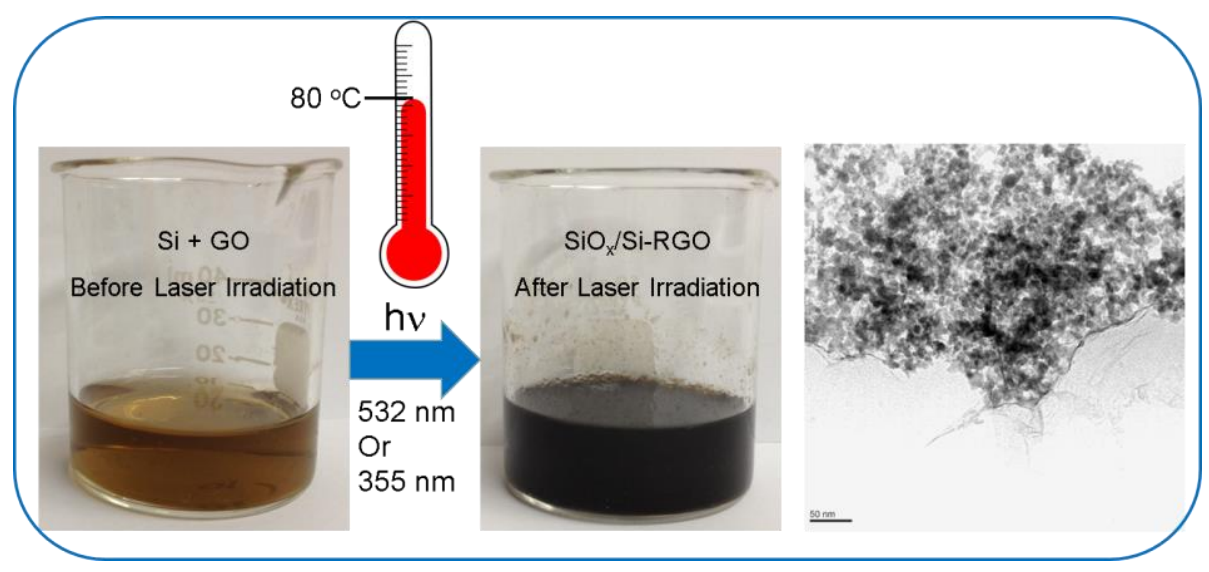

\begin{abstract}
$\underline{\text { Abstract }}$
We demonstrate the coupling of the photothermal effects of silicon nanocrystals with graphene oxide (GO) dispersed in water. Using laser irradiation (532 nm or $355 \mathrm{~nm}$ ) of suspended Si nanocrystals in an aqueous solution of GO, the synthesis of surface oxidized $\mathrm{Si}$-reduced GO nanocomposites $\left(\mathrm{SiO}_{\mathrm{x}} / \mathrm{Si}-\mathrm{RGO}\right)$ is reported. The laser reduction of GO is accompanied by surface oxidation of the Si nanocrystals resulting in the formation of the $\mathrm{SiO}_{\mathrm{x}} / \mathrm{Si}-\mathrm{RGO}$ nanocomposites. The $\mathrm{SiO}_{\mathrm{x}} / \mathrm{Si}-\mathrm{RGO}$ nanocomposites are proposed as promising materials for photothermal therapy and for the efficient conversion of solar energy into usable heat for a variety of thermal and thermomechanical applications.
\end{abstract}


Silicon nanostructures have been the subject of intense investigation for many years and the interest in the optical, photoluminescence and electrical properties of Si nanostructures continues to grow. ${ }^{1-4}$ In addition to the size-dependent photoluminescence properties of $\mathrm{Si}$ nanocrystals and their use in display and optoelectronic applications, their high-capacity as anode materials for $\mathrm{Li}$ ion batteries, especially when coupled with graphene, has been recently demonstrated. ${ }^{5.6}$ Furthermore, their biocompatible and biodegradable properties have triggered promising applications as in vivo imaging agents for a variety of applications in photothermal therapy and diagnosis. ${ }^{7-11}$

Plasmonic nanoparticles such as gold, silver and copper have been the most extensively studied systems for photothermal therapy applications. For example, gold nanostructures with different sizes and shapes have been employed in photothermal therapeutics due to their strongly enhanced absorption in the visible and NIR regions caused by their surface plasmon resonance (SPR) oscillations. ${ }^{12-14}$

In addition to gold nanoparticles, nanostructured carbon-based materials such as single wall carbon nanotubes, reduced graphene oxide (RGO) and GO have recently been applied in photothermal energy conversion as they can absorb light over extended regions of spectrum and convert it into heat through nonradiative decay processes. ${ }^{15-19}$ The large surface area of graphene and RGO and the strong optical absorption across the spectrum coupled with its high thermal and chemical stability can lead to a rapid temperature rise and subsequent energy transfer to the host medium, thus offering an efficient way of heating the medium. ${ }^{20-23}$ This has been demonstrated by the development of a facile laser reduction method for the synthesis of Laser Converted Graphene (LCG) which provides a solution processable synthesis of individual graphene sheets. ${ }^{24,25}$ In this process, irradiation of GO suspended in water using the second or the third harmonic of a Nd-YAG laser (532 nm or $355 \mathrm{~nm}$, respectively) results in significant deoxygenation of GO and the formation of LCG. This remarkable photothermal conversion of energy results in a significant temperature rise of water from room temperature to $75{ }^{\circ} \mathrm{C}$ in a few minutes of laser irradiation $(532 \mathrm{~nm}$ of nanosecond pulses at $30 \mathrm{~Hz}$ with an average power of 6 W). ${ }^{24}$

In this letter, we report enhanced photothermal effects with a new hybrid nanostructured material consisting of surface oxidized Si nanocrystals anchored to the surface of reduced GO nanosheets $\left(\mathrm{SiO}_{x} / \mathrm{Si}-\mathrm{RGO}\right)$. Hybrid materials composed of nanocarbons, such as the two- 
dimensional RGO, and semiconductor nanocrystals, such as silicon, could have important applications in photothermal therapy, solar cells, energy conversion and storing devices and nanoelectronics. Photothermal effects have been demonstrated for several semiconductor nanostructures such as $\mathrm{Si}$ nanowires ${ }^{26}$, porous $\mathrm{Si}^{27}$ and Ge nanocrystals. ${ }^{28}$ Recently, a near-IR photothermal response of photoluminescent $\mathrm{Si}$ nanocrystals has been demonstrated. ${ }^{11}$ However, there is no report on the photothermal energy conversion by surface oxidized Si nanocrystals anchored into RGO nanosheets. Here, we report on the laser surface oxidation of Si nanocrystals and the simultaneous reduction of GO to form surface oxidized $\mathrm{Si}$-RGO nanocomposites $\left(\mathrm{SiO}_{\mathrm{x}} / \mathrm{Si}-\mathrm{RGO}\right)$ as efficient photothermal agents for a variety of biomedical, thermal, thermochemical and thermomechanical applications. The availability of silicon, the second most abundant element in the Earth's crust, and the large production scale of graphite and GO coupled with the chemically inert nature of the $\mathrm{SiO}_{\mathrm{x}} / \mathrm{Si}-\mathrm{RGO}$ nanocomposites could make these proposed applications economically attractive possibilities.

Si nanocrystals were prepared using the Laser Vaporization Controlled Condensation (LVCC) method. ${ }^{29-31}$ The process consists of pulsed laser vaporization of a bulk Si target into an inert gas at well-defined temperatures and pressures inside a diffusion cloud chamber. ${ }^{29-31}$ GO was prepared by the oxidation of high purity graphite powder (99.9999\%, 200 mesh, Alfa Aesar) according to the method of Hummers and Offeman. ${ }^{32}$ After repeated washing of the resulting yellowish-brown cake with hot water, the powder was dried at room temperature under vacuum overnight. For the laser irradiation and photothermal measurements, ${ }^{20}$ aqueous dispersions ( $\left.3 \mathrm{ml}\right)$ of GO (prepared using $2 \mathrm{mg}$ solid GO in $10 \mathrm{ml}$ water) and preformed Si nanoparticles (1 mg or 2 mg Si nanoparticles in $3 \mathrm{ml}$ GO dispersion or in $3 \mathrm{ml}$ water for blank experiments) were prepared and each dispersion (3 $\mathrm{ml}$ of either $\mathrm{GO}$ in water or $\mathrm{Si}$ nanoparticles in water or $\mathrm{Si}$ nanoparticles in the GO dispersion) was irradiated in a quartz cuvette with the unfocused beam of the second and third harmonics of a Nd:YAG laser ( $2 \mathrm{nd}$ harmonic $\lambda=532 \mathrm{~nm}$, or $3 \mathrm{rd}$ harmonic $\lambda=355 \mathrm{~nm}$, pulse width $\tau=7 \mathrm{~ns}$, repetition rate $=30 \mathrm{~Hz}$, fluence $\sim 0.1 \mathrm{~J} / \mathrm{cm}^{2}$, Spectra Physics LAB-170-30). The beam diameter was measured to be 7-9 $\mathrm{mm}$ for both the $532 \mathrm{~nm}$ and $355 \mathrm{~nm}$. The solutions were magnetically stirred during the irradiation (irradiation for $10 \mathrm{~min}$ corresponding to 18,000 laser shots). The temperature of the solution was monitored during the laser irradiation using a thermocouple immersed in the solution. The $\mathrm{SiO}_{\mathrm{x}} / \mathrm{Si}-\mathrm{RGO}$ 
nanocomposite sheets were separated and dried overnight under vacuum before the XRD, Raman, IR and XPS measurements.

Fig. 1 represents typical TEM images of the Si nanocrystals prepared by the LVCC method using Ar and He carrier gases. ${ }^{29-31}$ The average sizes of the Si nanocrystals produced in 500 Torr Ar and 1000 Torr He are $5.5 \mathrm{~nm}$ and $4.5 \mathrm{~nm}$, respectively. The particles formed in He are smaller since the lighter carrier gas is more effective in removing the small particles away from the nucleation zone in the LVCC chamber before they can grow into larger particles. ${ }^{29-31}$ All the results reported below are obtained from the Si nanoparticles formed in 1000 Torr He.

(a)

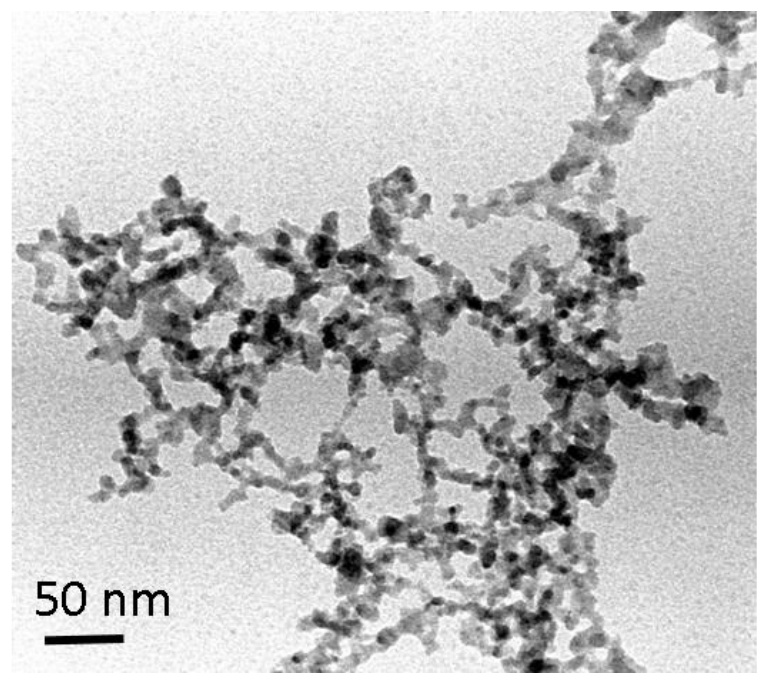

(b)

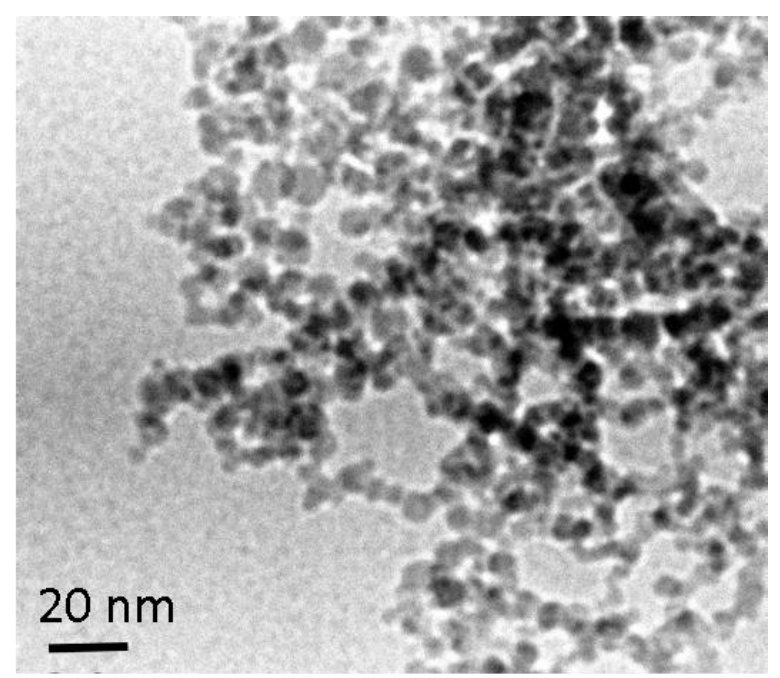

Fig. 1. TEM images of Si nanocrystals prepared by the LVCC method using 500 Torr Ar (a), and 1000 Torr He (b).

The XRD pattern of the exfoliated GO (Fig. S1(a), Supplementary Material) ${ }^{33}$ is characterized by a peak at $2 \theta=10.9^{\circ}$ with a larger d-spacing of $8.14 \AA$ (compared to the typical value of $3.34 \AA$ in graphite) resulting from the insertion of hydroxyl and epoxy groups between the carbon sheets and the carboxyl groups along the terminal and lateral sides of the sheets as a result 
of the oxidation process of graphite. ${ }^{24}$ As shown in Fig. S1(a), following the $532 \mathrm{~nm}$ or $355 \mathrm{~nm}$ laser irradiation in the presence of the Si nanocrystals, the $2 \theta=10.9^{\circ}$ completely disappears thus confirming the deoxygenation of the GO sheets and the restoration of the $\mathrm{sp}^{2}$ carbon sites in the RGO nanosheets. ${ }^{24,25}$ The $532 \mathrm{~nm}$ or $355 \mathrm{~nm}$ laser irradiation of GO in the presence of $\mathrm{Si}$ nanocrystals results in the disappearance of the $2 \theta=10.9^{\circ}$ diffraction peak similar to the laser irradiation of GO in the absence of Si nanoparticles. ${ }^{24}$ However, the extent of the laser reduction of GO could be more enhanced by the presence of Si nanoparticles as demonstrated below. The XRD pattern of the Si nanoparticles with the characteristic diffractions 111, 220, and 311 at scattering angles of $28^{\circ}, 47^{\circ}$, and $56^{\circ}$, respectively remains the same after the $355 \mathrm{~nm}$ or the $532 \mathrm{~nm}$ laser irradiation of the Si-GO solutions as shown in Fig. S1(b), thus indicating the presence of $\mathrm{Si}$ nanoparticles within the RGO nanosheets.

The UV-Vis absorption spectrum of GO (displayed in Fig. 2) shows significant absorption below $400 \mathrm{~nm}$ with the characteristic shoulder at $305 \mathrm{~nm}$ attributed to $\mathrm{n} \rightarrow \pi^{*}$ transitions of $\mathrm{C}=\mathrm{O}$ bonds. $^{24,25}$ This shoulder disappears after the $532 \mathrm{~nm}$ or the $355 \mathrm{~nm}$ irradiation of GO in the presence of Si nanocrystals as shown in Fig. 2, and the absorption peak of GO at $230 \mathrm{~nm}$ redshifts to longer than $250 \mathrm{~nm}$ due to the $\pi \rightarrow \pi^{*}$ transitions of extended aromatic C-C bonds. ${ }^{24,25}$ The absorption spectra following the $355 \mathrm{~nm}$ or the $532 \mathrm{~nm}$ laser irradiation of the Si-GO solution also show the absorption tail associated with the indirect band gap of the Si nanocrystals which extends from $400 \mathrm{~nm}$ across the visible region and the stronger absorption from 370 to $240 \mathrm{~nm} .{ }^{30}$ The UV-Vis spectra of Si nanocrystals in water, Si nanocrystals in GO dispersion before and after laser irradiation using the same absorbance scale are shown in Fig. S2 (Supplementary Material). ${ }^{33}$ 


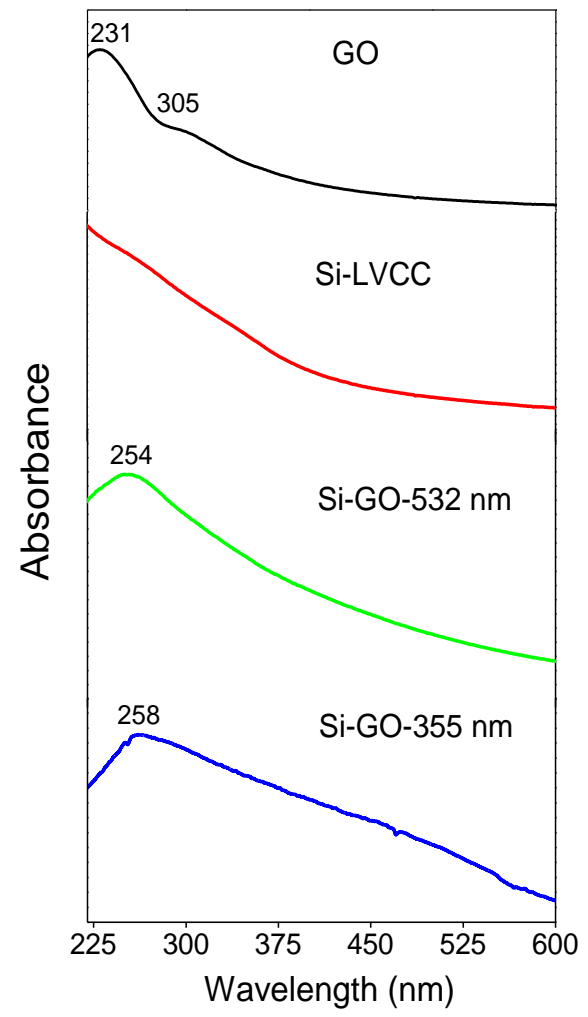

Fig. 2. UV-vis absorption spectra of GO (2 mg solid GO in $10 \mathrm{ml}$ water), Si nanoparticles prepared by the LVCC method (1 $\mathrm{mg} \mathrm{Si}$ nanoparticles in $3 \mathrm{ml}$ water), and Si nanoparticles-GO mixtures following laser irradiation using the $532 \mathrm{~nm}$ and $355 \mathrm{~nm}(1 \mathrm{mg} \mathrm{Si}$ nanoparticles in $3 \mathrm{ml} \mathrm{GO}$ dispersion above, $4 \mathrm{~W}$ laser power, $30 \mathrm{~Hz}, 10 \mathrm{~min}$ irradiation).

The XPS C1s spectrum of GO shows peaks corresponding to oxygen-containing groups between 285.5 and $289 \mathrm{eV}$ in addition to the $\mathrm{sp}^{2}$-bonded carbon $\mathrm{C}=\mathrm{C}$ at $284.5 \mathrm{eV}$ (Fig. 3-a). The oxygen-containing peaks disappear after the $532 \mathrm{~nm}$ or the $355 \mathrm{~nm}$ laser irradiation of the $\mathrm{Si}+\mathrm{GO}$ mixture indicating the formation of RGO in the Si-RGO nanocomposites. By comparing the XPS C1s spectra of the laser irradiated $\mathrm{Si}+\mathrm{GO}$ dispersions shown in Fig. 3 (a) with the spectrum obtained by the $532 \mathrm{~nm}$ laser irradiation of the GO solution without Si nanoparticles shown in Ref. 24 , it can be concluded that the extent of reduction of GO is higher in the presence of $\mathrm{Si}$ nanoparticles during the laser irradiation. This suggests that the presence of Si nanoparticles enhances the laser reduction of GO. This suggestion is confirmed by comparing the XPS spectra of the Si nanocrystals before and after the laser irradiation in the presence of GO as discussed below. 
The XPS spectrum of the Si nanocrystals (Fig. 3-b) shows two peaks at about 99.0 and 103.0 $\mathrm{eV}$ assigned to the $\mathrm{Si} 2 \mathrm{p}$ photoelectrons of the unoxidized $\mathrm{Si}$ core and the $\mathrm{SiO} x$ oxide layer, respectively. ${ }^{30,31}$ The ratio of the $99.0 \mathrm{eV}$ to the $103 \mathrm{eV}$ peaks indicates that the Si nanocrystals contain 48.5 at.\% Si on the surface. However, following the $532 \mathrm{~nm}$ or the $355 \mathrm{~nm}$ irradiation of the $\mathrm{Si}+\mathrm{GO}$ mixture, the $\mathrm{Si}$ content at the surface decreases to 11 at.\% or to 10.5 at.\%, respectively. This indicates that the laser reduction of GO is accompanied by a simultaneous oxidation of the surface of the Si nanocrystals anchored to the RGO nanosheets. This process results in more efficient reduction of $\mathrm{GO}$ in the surface oxidized $\mathrm{Si}$ nanocrystals-RGO nanocomposites $\left(\mathrm{SiO}_{\mathrm{x}} / \mathrm{Si}-\mathrm{RGO}\right)$.

(a)

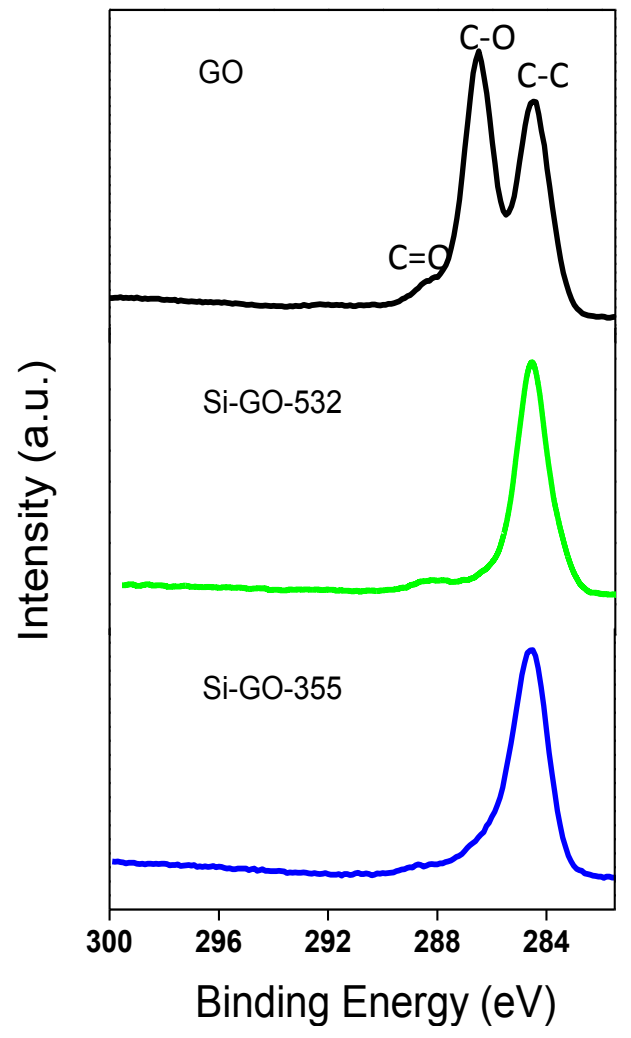

(b)

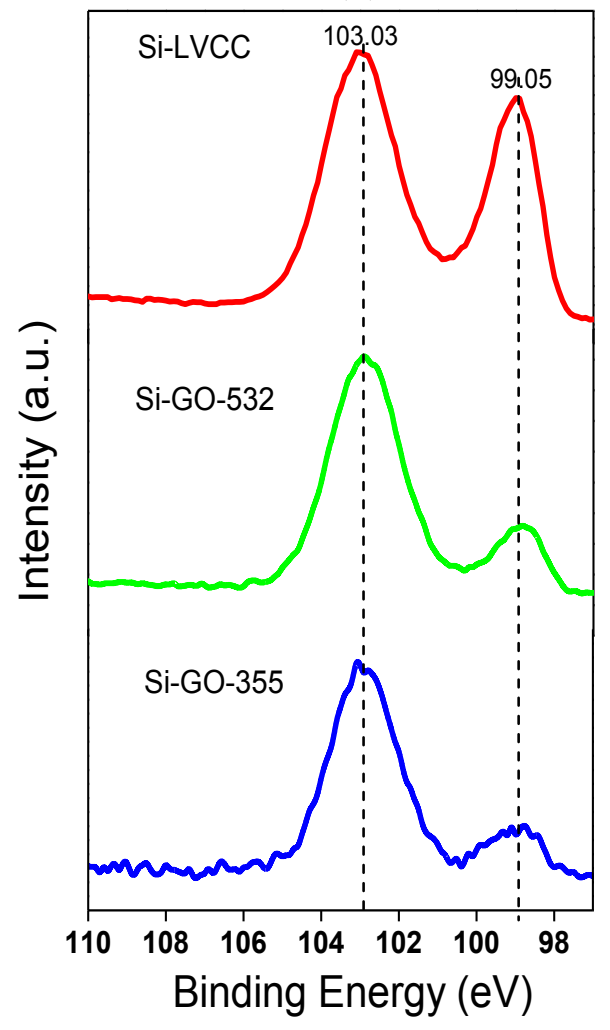

Fig. 3. XPS spectra of: (a) $\mathrm{C} 1 \mathrm{~s}$ of $\mathrm{GO}$ and the $\mathrm{SiO}_{\mathrm{x}} / \mathrm{Si}-\mathrm{RGO}$ nanocomposites prepared by $532 \mathrm{~nm}$ and $355 \mathrm{~nm}$ laser irradiation for $10 \mathrm{~min}$ in solution ( $1 \mathrm{mg}$ Si nanoparticles in $3 \mathrm{ml} \mathrm{GO}$ dispersion prepared using $2 \mathrm{mg}$ solid GO in $10 \mathrm{ml}$ water, $4 \mathrm{~W}$ laser power, $30 \mathrm{~Hz}$ ). (b) $\mathrm{Si} 2 \mathrm{p}$ of the $\mathrm{Si}$ nanocrystals prepared by the LVCC method and of the $\mathrm{SiO}_{\mathrm{x}} / \mathrm{Si}$-RGO nanocomposites described in (a). 
The Raman spectra of the prepared GO and the $\mathrm{Si}+\mathrm{GO}$ after laser irradiation using 532 $\mathrm{nm}$ or $355 \mathrm{~nm}(10 \mathrm{~min}, 4 \mathrm{~W}, 30 \mathrm{~Hz})$ are shown in Fig. 4. The spectrum of the exfoliated GO shows a broadened G-band $\left(1591 \mathrm{~cm}^{-1}\right)$ and a disorder-induced or defect D band at $1367 \mathrm{~cm}^{-1}$ with a $\mathrm{D}$ to $\mathrm{G}$ intensity ratio of about $0.70 .^{24,25}$ The G-band arises from the vibration of the $\mathrm{sp}^{2}$ bonded carbon atoms and the D-band is attributed to structural disorder at defect sites with the $\mathrm{D} / \mathrm{G}$ ratio usually taken as a measure of the quality of the graphitic structures since for highly ordered pyrolitic graphite, this ratio approaches zero. ${ }^{34,35}$ The $532 \mathrm{~nm}$ or the $355 \mathrm{~nm}$ laser irradiation of $\mathrm{Si}+\mathrm{GO}$ results in incorporating the surface-oxidized $\mathrm{Si}$ nanocrystals within the RGO nanosheets $\left(\mathrm{SiO}_{\mathrm{x}} / \mathrm{Si}-\mathrm{RGO}\right)$ which leads to a significant shift of the $\mathrm{D}$ band to lower frequency and to increasing the intensity ratio of the $\mathrm{D} / \mathrm{G}$ bands to 1.1 (by $532 \mathrm{~nm}$ irradiation) or to 1.3 (by $355 \mathrm{~nm}$ irradiation) as shown in Fig. 4. The increase in the intensity ratio of the D/G bands after the laser irradiation of the GO solutions containing the Si nanoparticles indicates the presence of more structural defects in the Si-containing RGO lattice induced by laser irradiation of $\mathrm{GO}$ in the presence of $\mathrm{Si}$ nanoparticles. These defect sites could act as favorable sites to anchor the Si nanoparticles on the RGO nanosheets. Another important change in the Raman spectra of GO following the laser irradiation in the presence of Si nanoparticles is the significant shift observed in the $\mathrm{G}$ band toward higher frequency from $1591 \mathrm{~cm}^{-1}$ in GO to $1610 \mathrm{~cm}^{-1}$ in the $\mathrm{SiO}_{\mathrm{x}} / \mathrm{Si}-\mathrm{RGO}$ nanosheets. The shift in the $\mathrm{G}$ band $\left(18 \mathrm{~cm}^{-1}\right)$ is very significant and is consistent with the Raman data of graphene sheets decorated with ultrathin Si-rich two-dimensional islands in which the electronic property of graphene is modulated by coupling with the Si-islands. ${ }^{36}$ 


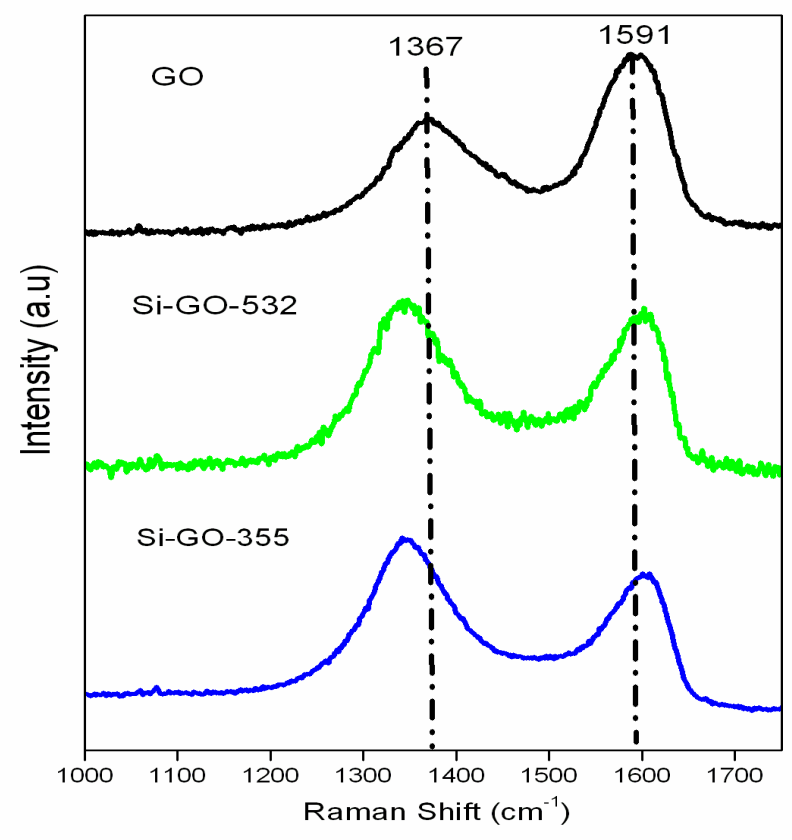

Fig. 4. Raman spectra of GO and Si-RGO nanocomposites prepared by $532 \mathrm{~nm}$ and $355 \mathrm{~nm}$ laser irradiation for $10 \mathrm{~min}$ in solution (1 $\mathrm{mg}$ Si nanoparticles in $3 \mathrm{ml} \mathrm{GO}$ dispersion prepared using 2 mg solid GO in $10 \mathrm{ml}$ water, $4 \mathrm{~W}$ laser power, $30 \mathrm{~Hz}$ ).

Figs 5 (a) and (b) display TEM images of the Si nanocrystals dispersed in the GO solution before laser irradiation. The images show that the Si nanocrystals are not well dispersed within the GO nanosheets and that both the Si nanoparticles and GO nanosheets appear to be segregated in separate regions of the TEM grid. However, following the laser irradiation of the Si nanoparticlesGO solutions, the $\mathrm{SiO}_{\mathrm{x}} / \mathrm{Si}$ nanocrystals appear to be well-dispersed across the RGO nanosheets as shown in Figs 5(c, d) and 5(e,f) for the $355 \mathrm{~nm}$ and 532 laser irradiations, respectively. Fig. 5(f) shows that increasing the concentration of the Si nanocrystals from 1 to $2 \mathrm{mg}$ in $3 \mathrm{ml} \mathrm{GO}$ results in more aggregation of the $\mathrm{SiO}_{x} / \mathrm{Si}$ nanocrystals, although the aggregated nanocrystals remain distributed across the RGO nanosheets with no evidence for segregation between the $\mathrm{Si}$ nanocrystals and the RGO nanosheets. 

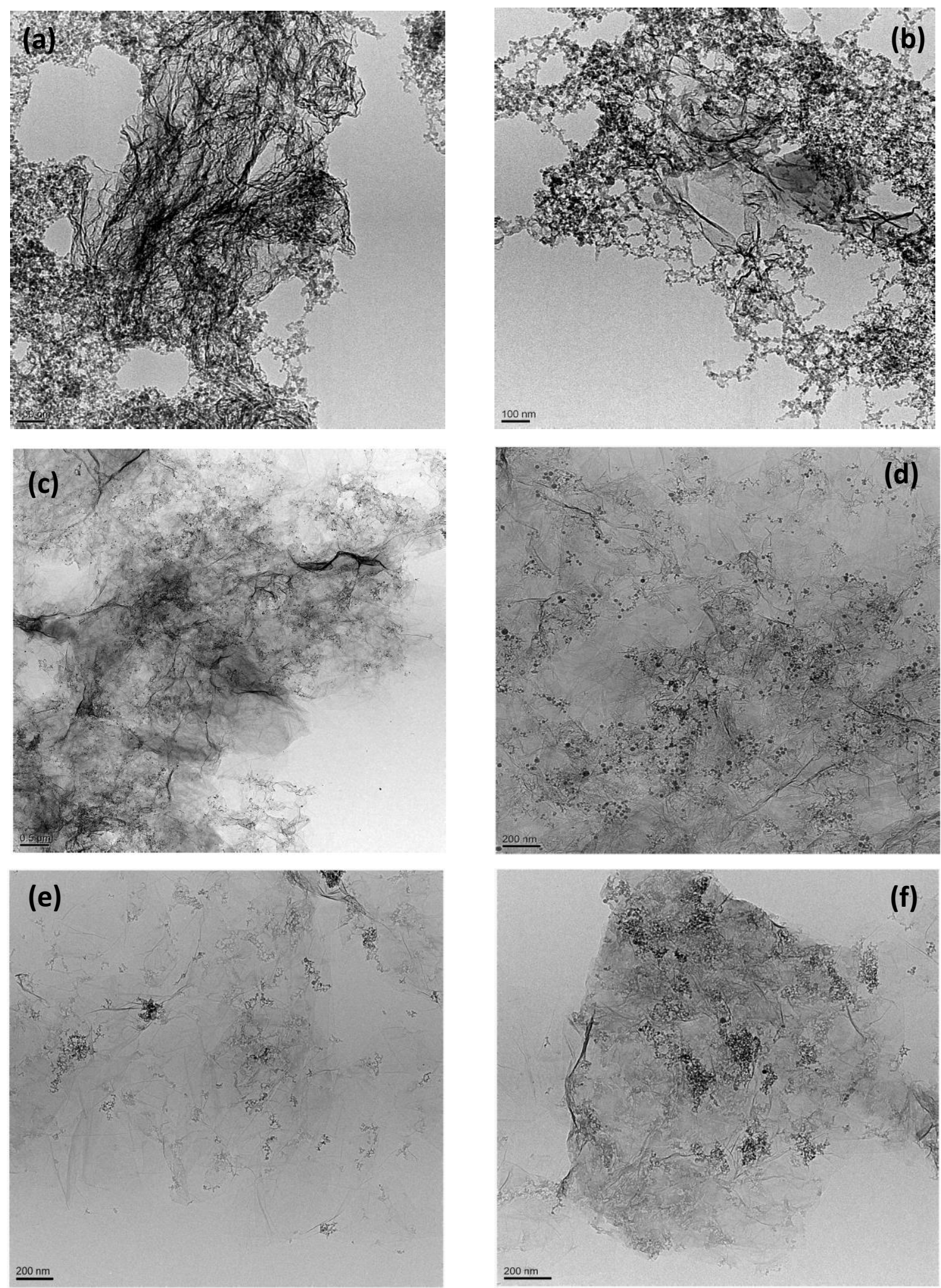

Fig. 5. TEM images of Si nanocrystals suspended in GO solution without laser irradiation (a and b) and $\mathrm{SiO}_{\mathrm{x}} / \mathrm{Si}-\mathrm{RGO}$ nanocomposites prepared by laser irradiation $(10 \mathrm{~min})$ of the $\mathrm{Si}$ nanoparticles in $\mathrm{GO}$ using $355 \mathrm{~nm}$ (c and d) and $532 \mathrm{~nm}$ (e and f). The concentrations of the Si nanoparticles were $1 \mathrm{mg} \mathrm{Si}$ nanoparticles in $3 \mathrm{ml} \mathrm{GO}$ dispersion in images a-e, and $2 \mathrm{mg}$ Si nanoparticles in $3 \mathrm{ml} \mathrm{GO}$ dispersion in image (f). The GO dispersion was prepared using $2 \mathrm{mg}$ solid GO in $10 \mathrm{ml}$ water. 
The above results indicate that laser irradiation of mixtures of Si nanocrystals and GO in water using $532 \mathrm{~nm}$ or $355 \mathrm{~nm}$ results in simultaneous surface oxidation of the Si nanocrystals and reduction of the GO leading to the formation $\mathrm{SiO}_{\mathrm{x}} / \mathrm{Si}-\mathrm{RGO}$ nanocomposites as evident by the changes occurring in the XRD, UV-Vis, Raman and XPS data of the mixtures following the laser irradiation. It should be noted that mixtures of $\mathrm{Si}$ nanocrystals and $\mathrm{GO}$ in water without laser irradiation do not result in any significant changes in the XRD, UV-Vis, Raman and XPS spectra of the individual Si nanocrystals and GO components. This is consistent with the very slow dissolution rate of Si nanoparticles in deionized water at room temperature ( $<0.1 \mathrm{~nm}$ per day) due to the absence of ions. ${ }^{37}$ Therefore, the formation of the $\mathrm{SiO}_{\mathrm{x}} / \mathrm{Si}-\mathrm{RGO}$ nanocomposite is mediated by the simultaneous laser reduction of GO and surface oxidation of the Si nanocrystals in water.

Figs. 6 (a) and (b) display the measured temperature changes caused by $532 \mathrm{~nm}$ and 355 $\mathrm{nm}$ laser irradiation, respectively of dispersions of Si nanoparticles in water, GO in water and mixtures of Si nanoparticles + GO dispersions under identical experimental conditions. Both GO and Si nanoparticles show significant photothermal effects. The temperature of the GO dispersion (3 ml) containing $1 \mathrm{mg}$ Si nanoparticles reaches $64{ }^{\circ} \mathrm{C}$ after 10 minutes of laser irradiation (532 $\mathrm{nm}, 4 \mathrm{~W}, 30 \mathrm{~Hz})$ in comparison with the same concentration of Si nanoparticles in water $(1 \mathrm{mg} / 3$ $\mathrm{ml}$ ), and the $\mathrm{GO}$ solution $(3 \mathrm{ml})$ without $\mathrm{Si}$ nanoparticles which reach $43{ }^{\circ} \mathrm{C}$ and $57{ }^{\circ} \mathrm{C}$, respectively under identical experimental conditions as shown in Fig. 6 (a). Increasing the concentration of the $\mathrm{Si}$ nanocrystals from $1 \mathrm{mg} / 3 \mathrm{ml} \mathrm{GO}$ to $2 \mathrm{mg} / 3 \mathrm{ml} \mathrm{GO}$ results in a temperature rise to $68^{\circ} \mathrm{C}$ after 10 minutes of the $532 \mathrm{~nm}$ laser irradiation as shown in Fig. 6 (a). Similar results are obtained using the $355 \mathrm{~nm}$ laser irradiation where the temperature rise of the $1 \mathrm{mg} \mathrm{Si}$ dispersion in $3 \mathrm{ml} \mathrm{GO}$ reaches $50{ }^{\circ} \mathrm{C}$ after 10 minutes as compared to the $355 \mathrm{~nm}$ irradiation of the separate $\mathrm{Si}$ and GO dispersions where the temperature reaches $46{ }^{\circ} \mathrm{C}$ and $44{ }^{\circ} \mathrm{C}$, respectively under identical experimental conditions as shown in Fig. 6 (b). In both the $532 \mathrm{~nm}$ and $355 \mathrm{~nm}$ laser irradiation, the pure water shows negligible temperature rise as shown in Figs 6 (a) and (b). However, the rate of increasing the temperature of the Si nanocrystals + GO solutions appears to decrease at longer irradiation times ( $<5$ minutes with laser power $4 \mathrm{~W}, 30 \mathrm{~Hz}$ ) and the temperature rise appears to reach a plateau especially with the $355 \mathrm{~nm}$ irradiation as shown in Fig. 6(b). This could be explained by the instability of the RGO under longer times of laser irradiation by the 355 $\mathrm{nm}$ photons. The resulting RGO appears to be more stable under the $532 \mathrm{~nm}$ than under the 355 
$\mathrm{nm}$ laser irradiation at longer irradiation times. However, by limiting the laser irradiation times to 5 minutes (532 nm, $4 \mathrm{~W}, 30 \mathrm{~Hz}$ or 9,000 pulses), we were able to repeat the heating (laser on) and cooling (laser off) cycles reproducibly over seven cycles with almost the same temperature profiles. The temperature of the solution returns to room temperature after the laser is turned off at almost the same rate as heating occurs during laser irradiation.

The higher temperature rise observed for the Si nanoparticles dispersed in the GO solution demonstrates that the coupling of the photothermal effects of Si nanoparticles and GO can result in highly efficient photothermal energy convertors.

(a)

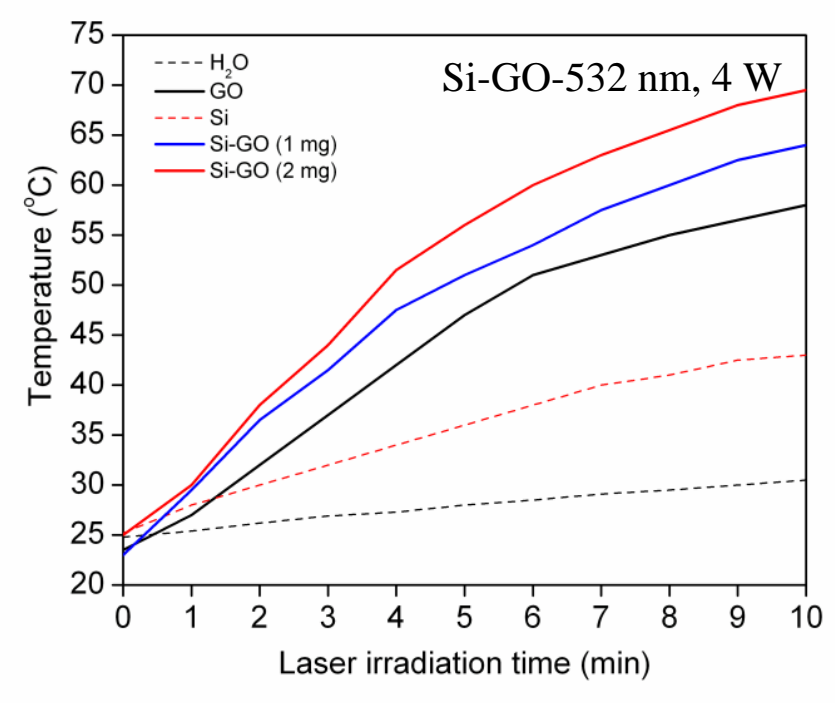

(b)

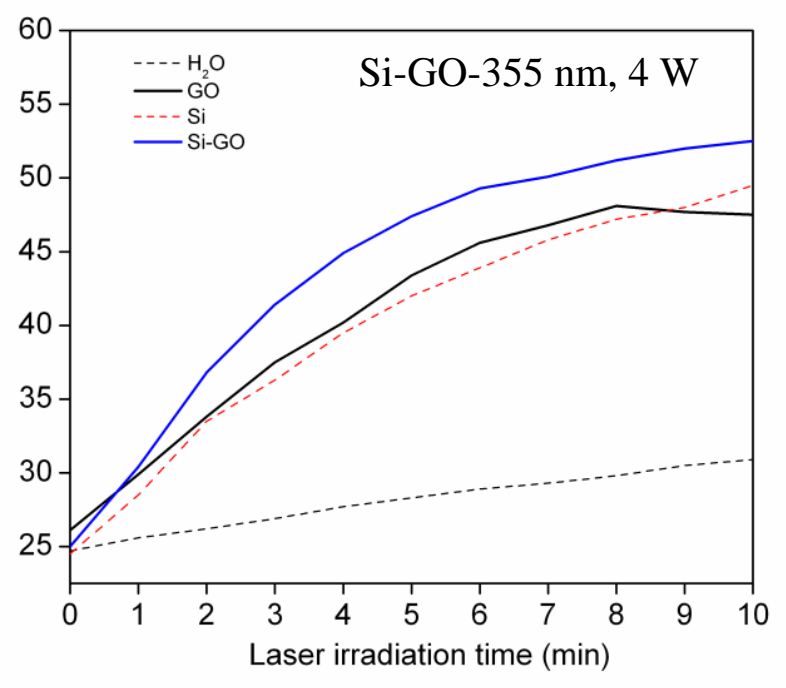

Fig. 6. Photothermal effects of Si nanoparticles, GO and their mixtures in water using laser irradiation with (a) $532 \mathrm{~nm}$ and (b) $355 \mathrm{~nm}$.

In summary, the coupling of the laser reduction of graphene oxide with the surface oxidation of $\mathrm{Si}$ nanoparticles leads to a significant enhancement of the efficiency of photothermal energy conversion by the $\mathrm{Si}$ nanoparticles-graphene oxide mixtures. The large surface areas of the RGO nanosheets with multiple defect sites and vacancies provide efficient sites for the surface oxidized Si nanocrystals to be anchored to the RGO nanosheets. The $\mathrm{SiO}_{\mathrm{x}} / \mathrm{Si}-\mathrm{RGO}$ nanocomposites are proposed as novel photothermal energy convertors for a 
variety of thermochemical and thermomechanical applications, in addition to photothermal therapy, such as heating and evaporation of liquids by solar energy, ignition of solid fuels, and welding of composite materials.

\section{Acknowledgements}

We thank the National Science Foundation (CHE-1463989) for the support of this work.

\section{References}

1. L. Pavesi, L. D. Negro, C. Mazzoleni, G. Franzo and F. Priolo, Nature 408, 440 (2000).

2. Y. Y. Su, X. P. Wei, F. Peng, Y. L. Zhong, Y. M. Lu, S. Su, T. T. Xu, S. T. Lee, and Y. He, Nano Lett. 12, 1845 (2012).

3. S. P. Song, Y. Qin, Y. He, Q. Huang, C. H. Fan, and H. Y. Chen, Chem. Soc. Rev. 39, 4234 (2010).

4. M. Dasog, Z. Yang, S. Regli, T. M. Atkins, A. Faramus, M. P. Singh, E. Muthuswamy, S. M. Kauzlarich, R. D. Tilley and J. G. C. Veinot, ACS Nano 7, 2676 (2013).

5. J. Luo, X. Zhao, J. Wu, H. D. Jang, H. H. Kung and J. Huang, J. Phys. Chem. Lett. 3, 1824 (2012).

6. A. R. Park, J. S. Kim, K. S. Kim, K. Zhang, J. Park, J. H. Park, J. K. Lee and P. J. Yoo, ACS Appl. Mater. 6, 1702 (2014).

7. Y. Zhong, F. Peng, F. Bao, S. Wang, X. Ji, L. Yang, Y. Su, S-T. Lee and Y. He, J. Am. Chem. Soc. 135, 8350 (2013).

8. J. H. Park, L. Gu, G. von Maltzahn, E. Ruoslahti, S. N. Bhatia, and M. J. Sailor, Nat. Mater. 8, 331 (2009).

9. F. Erogbogbo, K. T. Yong, I. Roy, R. Hu, W. C. Law, W. W. Zhao, H. Ding, F. Wu, R. Kumar, M. Swihart, and P. N. Prasad, ACS Nano 5, 413 (2011).

10. B. A. Manhat, A. L. Brown, L. A. Black, J. B. Alexander, K. Fixher, T. Vu, E. Richman and A. M. Goforth, Chem. Mater. 23, 2407 (2011).

11. S. Regli, J. A. Kelly, A. M. Shukaliak and J. G. C. Veinot, J. Phys. Chem. Lett. 3, 1793 (2012).

12. S. Eustis and M. A. El-Sayed, Chem. Soc. Rev. 35, 209 (2006).

13. J. Z. Zhang, J. Phys. Chem. Lett. 1, 686 (2010).

14. E. C. Dreaden, M. A. Mackey, X. H. Huang, B. Kang and M. A. El-Sayed, Chem. Soc. Rev. 40, 3391 (2011). 
15. P. Chakravarty, R. Marches, N. S. Zimmerman, A. D. E. Swafford, P. Bajaj, I. H. Musselman, P. Pantano, R. K. Draper, E. S. Vitetta, Proc. Natl.Acad. Sci. U.S.A. 105, 8697 (2008).

16. S. Ghosh, S. Dutta, E. Gomes, D. Carroll, R. D’Agostino, J. Olson, M. Guthold, and W. H. Gmeiner, ACS Nano 3, 2667 (2009).

17. Z. Liu, J. T. Robinson, X. Sun, H. Dai, J. Am. Chem. Soc. 130, 10876 (2008).

18. K. Yang, S. Zhang, G. Zhang, X. Sun, S. T. Lee, and Z. Liu, Z, Nano Lett. 10, 3318 (2010).

19. J. T. Robinson, S. M. Tabakman, Y. Liang, H. Wang, H. S. Casalongue, D. Vinh, H. Dai, J. Am. Chem. Soc. 133, 6825 (2011).

20. A. F Zedan, S. Moussa, J. Terner, G. Atkinson and M. S. El-Shall, ACS Nano 7, 627 (2013).

21. D-K. Lim, A. Barhoumi, R. G. Wylie, R. S. Langer and D. S. Kohane, Nano Lett. 13, 4075 (2013).

22. O. Akhavan and E. Ghaderi, Small 9, 3593 (2013).

23. Z. Gan, X. Wu, M. Meng, X. Zhu, L. Yang, and P. K. Chu, ACS Nano 8, 9304 (2014).

24. V. Abdelsayed, S. Moussa, H. M. Hassan, H. S. Aluri, M. M. Collinson, and M. S. El-Shall, J. Phys. Chem. Lett. 1, 2804 (2010).

25. S. Moussa, G, Atkinson, M. S. El-Shall, A. Shehata, K. M. AbouZeid, M. B. Mohamed, J. Mater. Chem. 21, 9608 (2011).

26. N. Wang, B. D. Yao, Y. F. Chan and X. Y. Zhang, Nano Lett. 3, 475 (2003).

27. C. Lee, H. Kim, C. Hong, M. Kim, S. S. Hong, D. H. Lee, and W. I. Lee. J. Mater. Chem. 18, 4790 (2008).

28. T. N. Lambert, N. L. Andrews, H. Gerung, T. J. Boyle, J. M. Oliver, B. S. Wilson, and S. M. Han, Small 3, 691-699 (2007).

29. M. S. El-Shall, Chapter 4, pp 167-201, in "Nanomaterials: Processing and Characterization with Lasers", Editors: S. C. Singh, H. B. Zeng, C. Guo, and W. P. Cai, Chapter Wiley-VCH, Verlag GmbH \& Co. KGaA (2012).

30. I. N. Germanenko, S. Li and M. S. El-Shall, J. Phys. Chem. 105, 59 (2001).

31. S. Li, S. Silvers and M. S. El-Shall, J. Phys. Chem. 101, 1794 (1997).

32. W. S. Hummers, Jr. and R. E. Offeman, J. Am. Chem. Soc. 80, 1339 (1958).

33. See Supplementary Material Document No for experimental details and XRD of GO, Si nanoparticles and Si-RGO nanocomposites prepared by laser irradiation of GO + Si nanoparticles mixtures in water. (Figure S1). For information on Supplementary Material, see http://www.aip.org/pubservs/epaps.html.

34. A. C. Ferrari, Solid State Commun. 446, 60 (2007). 
35. L. G. Cancado, A. Jorio, E. H. Martins Ferreira, F. Stavale, C. A. Achete, R. B. Capaz, M. V. O. Moutinho, A. Lombardo, T. S. Kulmala, A. C. Ferrari, Nano Lett. 11, 3190 (2011).

36. D. H. Lee, J. Yi, J. M. lee, S. J. lee, Y-J. Doh, H. Y. J.; Z. Lee, U. Paik, J. A. Rogers and W. I. Park, ACS Nano 7, 301 (2013).

37. L. Yin, A. B. Farimani, K. Min, N. Vishal, J. Lam, Y. K. Lee, N. R. Aluru and J. A. Rogers, Adv. Mater. 27, 1857 (2015). 